\title{
A comparison of food sources of nudibranch mollusks at different depths off the Kuril Islands using fatty acid trophic markers
}

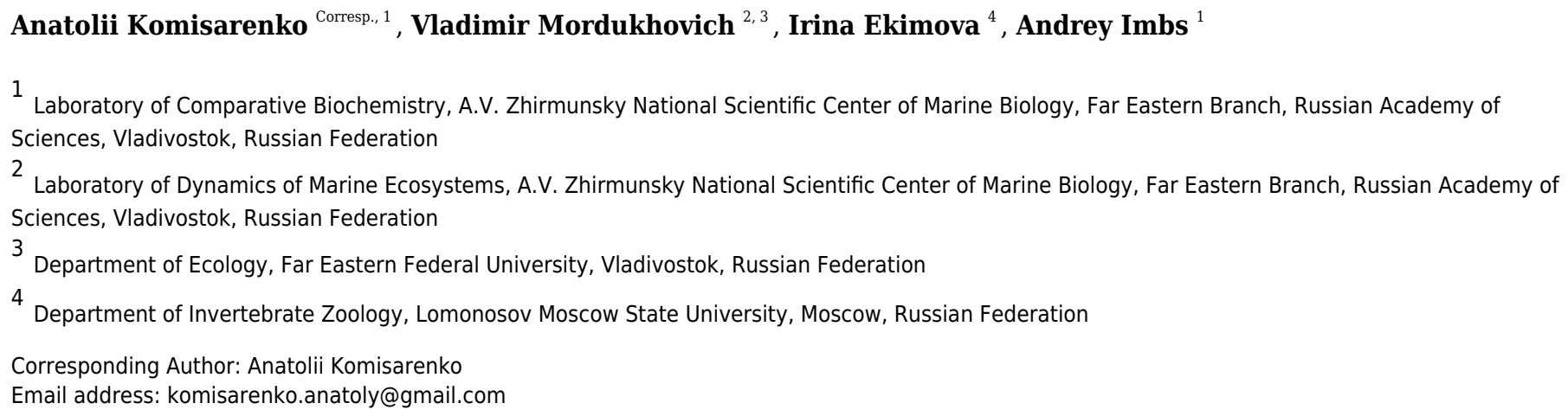

Gastropod molluscs such as nudibranchs are important members of deep-sea benthic ecosystems. However, data on the trophic ecology and feeding specialization of these animals are limited to date. The method of fatty acid trophic markers (FATM) was applied to determine the dietary preferences of nudibranchs off the Kuril Islands. Fatty acid (FA) compositions of Dendronotus sp., Tritonia tetraquetra, and Colga pacifica collected from deep waters were analyzed and compared with those of Aeolidia papillosa and Coryphella verrucosa from the offshore zone. The high level of FATM such as 22:5n-6 and $C_{20}$ monounsaturated FAs indicated that Dendronotus sp. preys on sea anemones and/or anthoathecates hydroids similarly to that of shallow-water species $A$. papillosa and $C$. verrucosa. The high percentage of tetracosapolyenoic acids and the ratio 24:6n-3/24:5n-6 indicated that $T$. tetraquetra preys on soft corals such as Gersemia and/or Acanella at a depth of $250 \mathrm{~m}$, but soft corals of the family Primnoidae may be the main item in the diet of $T$. tetraquetra at a depth of $500 \mathrm{~m}$. The high content of $\Delta 7,13-22: 2$ and $22: 6 \mathrm{n}-3$ shows that $C$. pacifica can feed on bryozoans. In C. pacifica, 22:5n-6 may be synthesized intrinsically by the mollusks, whereas odd-chain and branched saturated FAs originate from associated bacteria. 
1 A comparison of food sources of nudibranch

2 mollusks at different depths off the Kuril Islands using

3 fatty acid trophic markers

4

5

6

7

8

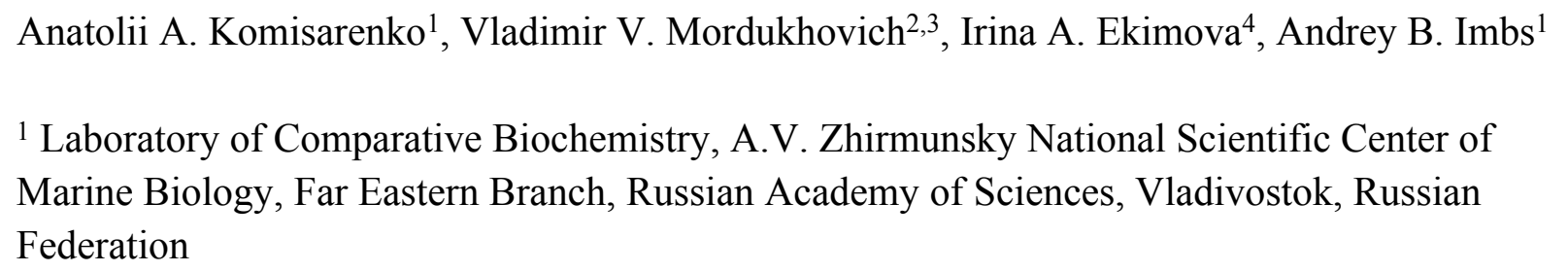

${ }^{2}$ Laboratory of Dynamics of Marine Ecosystems, A.V. Zhirmunsky National Scientific Center of Marine Biology, Far Eastern Branch, Russian Academy of Sciences, Vladivostok, Russian Federation

${ }^{3}$ Department of Ecology, Far Eastern Federal University, Vladivostok, Russian Federation

${ }^{4}$ Department of Invertebrate Zoology, Lomonosov Moscow State University, Moscow, Russian Federation

Corresponding Author:

Anatolii Komisarenko

Palchevskogo str., 17, Vladivostok 690041, Russian Federation

Email address: komisarenko.anatoly@gmail.com

\section{Abstract}

Gastropod molluscs such as nudibranchs are important members of deep-sea benthic ecosystems. However, data on the trophic ecology and feeding specialization of these animals are limited to date. The method of fatty acid trophic markers (FATM) was applied to determine the dietary preferences of nudibranchs off the Kuril Islands. Fatty acid (FA) compositions of Dendronotus sp., Tritonia tetraquetra, and Colga pacifica collected from deep waters were analyzed and compared with those of Aeolidia papillosa and Coryphella verrucosa from the offshore zone. The high level of FATM such as $22: 5 \mathrm{n}-6$ and $\mathrm{C}_{20}$ monounsaturated FAs indicated that Dendronotus sp. preys on sea anemones and/or anthoathecates hydroids similarly to that of shallow-water species $A$. papillosa and $C$. verrucosa. The high percentage of tetracosapolyenoic acids and the ratio 24:6n-3/24:5n-6 indicated that $T$. tetraquetra preys on soft corals such as Gersemia and/or Acanella at a depth of $250 \mathrm{~m}$, but soft corals of the family Primnoidae may be the main item in the diet of $T$. tetraquetra at a depth of $500 \mathrm{~m}$. The high content of $\Delta 7,13-22: 2$ and 22:6n-3 shows that $C$. pacifica can feed on bryozoans. In C. pacifica, 22:5n-6 may be synthesized intrinsically by the mollusks, whereas odd-chain and branched saturated FAs originate from associated bacteria. 
40

41 Subjects Biochemistry, Marine Biology, Aquatic and Marine Chemistry

42

43

44

45

46

47

48

49

50

51

52

53

54

55

56

57

58

59

60

61

62

63

64

65

66

67

68

69

70

71

72

73

74

75

76

77

78

79

Keywords Nudibranchia, Cold-water species, Dietary fatty acids, Lipids, Food webs

\section{Introduction} Cuvier, 1817). The greatest diversity of nudibranchs is observed in warm shallow waters, hydroids, and other nudibranchs (Barnes \& Bullough, 1996; McDonald \& Nybakken, 1997, et al., 2020).

Fatty acids (FAs) have been used as biochemical markers to trace predator-prey 1870 collected in the Kurile Islands region (Imbs, 2016; Imbs \& Chernyshev, 2019; Imbs \& The detection of large amounts of dietary FAs in T. tetraquetra (Imbs, 2016; Imbs \& trophic ecology of cold-water nudibranchs. are a common animal group of this area and, therefore, play an important role on trophic

Nudibranchs are a group of marine soft-bodied gastropod mollusks (Gastropoda: Nudibranchia although nudibranchs occur worldwide, from Arctic to Antarctic regions, with some species discovered at a depth near $2500 \mathrm{~m}$ (Ekimova et al., 2015; Bertsch, 2020). Identification of food sources of nudibranchs is important for understanding their ecology and description of trophic interactions in marine benthic ecosystems (Ekimova et al., 2019b). Nudibranchs are mostly carnivorous, but detritus and microalgae may comprise some part of their diet (Ekimova, Deart \& Schepetov, 2019a; Ekimova et al., 2019b). Nudibranch can feed on soft corals, reef-building corals, sponges, bryozoans, tunicates, barnacles, sea anemones, jellyfish, ophiuroids, colonial 1999; Goodheart et al., 2017). Many nudibranch species exhibit high dietary specialization (Hoover et al., 2012; Goodheart et al., 2017; Ekimova et al., 2019b; Imbs \& Grigorchuk, 2019; Mikhlina et al., 2018, Mikhlina, Ekimova \& Vortsepneva, 2020). In contrast to shallow-water species, data on feeding regimes of deep-sea nudibranch species still remain limited (Chimienti relationships in marine ecosystems for more than 40 years (Budge, Iverson \& Koopman,2006; Kelly \& Scheibling, 2012; Braeckman et al., 2015; Calado \& Leal, 2015;). The method of FA trophic markers (FATM) was already successfully applied to determine possible origins of food in several nudibranch species from tropical shallow waters (Zhukova, 2014) and the deep-sea nudibranchs Tritonia tetraquetra (Pallas, 1788), Dendronotus sp., and D. robustus A.E. Verril, Grigorchuk, 2019). FATM showed that Dendronotus sp. and T. tetraquetra prey on different species of cold-water soft corals, while D. robustus may consume hydrocorals and bryozoans (Imbs \& Grigorchuk, 2019). The difference in food sources between these two species belonging to the same genus (Dendronotus) and inhabiting the same waters was detected by using FATM. Chernyshev, 2019) showed that the FATM method could be successfully apply for the study of

Waters around the Kuril Islands, with their significant depth differences, are one of the world's most productive marine ecosystem (Shuntov, Ivanov \& Dulepova, 2019). Nudibranchs dynamics in the ecosystem studied. To expand our knowledge on trophic ecology of deep-sea mollusks, FA composition of total lipids of three nudibranch species (Colga pacifica (Bergh, 1894), Tritonia tetraquetra, and Dendronotus sp.) collected from deep waters (up to $500 \mathrm{~m}$ ) were

Peer] reviewing PDF | (2021:06:63125:2:0:NEW 17 Sep 2021) 
80

81

82

83

84

85

86

87

88

89

90

91

92

93

94

95

96

97

98

99

100

101

102

103

104

105

106

107

108

109

110

111

112

113

114

115

116

117

118

119

analyzed and compared with those of two nudibranch species (Aeolidia papillosa (Linnaeus, 1761) and Coryphella verrucosa (M. Sars, 1829)) from the offshore zone (about $20 \mathrm{~m}$ ) of the

Kurile Islands. Dietary preferences of these five species were studied using the method of

FATM. A possible influence of depth on nudibranch feeding specialization was discussed.

\section{Materials and Methods} Sample collection

Sampling was conducted aboard the R/V Akademik Oparin near Simushir Island (Kuril Islands, Sea of Okhotsk, $47^{\circ} 08^{\prime} \mathrm{N}, 152^{\circ} 14^{\prime} \mathrm{E}$ ) in July 2019. In total, 18 nudibranchs were sampled. Three specimens of C. verrucosa and 2 specimens of A. papillosa were collected at a depth of $20 \mathrm{~m}$ by SCUBA and referred as a shallow-water group. Three specimens of $C$. pacifica, 3 specimens of Dendronotus sp., and 5 specimens of $T$. tetraquetra were collected at the depth of $250-500 \mathrm{~m}$ by dredging and referred as a deep-sea group. The nudibranch Dendronotus sp. was different from the one already reported (Imbs \& Grigorchuk, 2019). Each specimen sampled was photographed (Fig. 1); one piece of foot tissue was fixed in $96 \% \mathrm{EtOH}$ for molecular analysis to confirm the identification of nudibranchs according to Ekimova et al. (2019b); another piece of foot tissue was frozen at $-80{ }^{\circ} \mathrm{C}$ for lipid analysis. Unfortunately, two frozen samples (one for $A$. papillosa and one for T. tetraquetra) were lost in transit.

\section{Morphological analysis}

To study the radular morphology of each species, the buccal mass was extracted and soaked in proteinase $\mathrm{K}$ solution for 2 hours at $60^{\circ} \mathrm{C}$. When connective and muscle tissues were dissolved, samples were rinsed in distilled water, air-dried, mounted on an aluminium stub, and sputtercoated with gold for visualization under a JEOL JSM 6380 scanning electron microscope. The radular morphology of each species is shown in Figure 2.

\section{Lipid preparation and fatty acid analysis}

Lipids were extracted from the specimens as described by Bligh and Dyer (1959). FA methyl ethers (FAME) were prepared using the method of Carreau and Dubacq (1978) and were purified by preparative thin-layer chromatography in benzene. The 4,4-dimethyloxazoline (DMOX) derivatives of FA were prepared according to the method of Svetashev (2011). A gas chromatography analysis of FAME was conducted with a GC-2010 chromatograph (Shimadzu, Kyoto, Japan) with a flame ionization detector. A Supelcowax 10 (Supelco, Bellefonte, USA) capillary column $(30 \mathrm{~m} \times 0.25 \mathrm{~mm}$ ID, film thickness $25 \mu \mathrm{m})$ was held for $2 \mathrm{~min}$ at $170{ }^{\circ} \mathrm{C}$, then heated with a $2{ }^{\circ} \mathrm{C} \cdot \mathrm{min}^{-1}$ ramp to $240^{\circ} \mathrm{C}$ that was held for $5 \mathrm{~min}$. A sample volume of $1 \mu \mathrm{L}$ (about $\left.1 \mathrm{mg} \cdot \mathrm{mL}^{-1}\right)$ was injected. The injector $\left(250^{\circ} \mathrm{C}\right)$ and detector $\left(260^{\circ} \mathrm{C}\right)$ temperatures were constant. Helium was used as the carrier gas at a linear velocity of $30 \mathrm{~cm} \cdot \mathrm{s}^{-1}$. FAME peaks were analyzed by comparing their retention time with those of the standards (a mixture of PUFA methyl esters No. 3 from menhaden oil, Sigma-Aldrich Co., USA). The concentrations of individual FAs were calculated from the integrated area ( $\%$ of total FAs). Identification of FAs 
120

121

122

123

124

125

126

127

128

129

130

131

132

133

134

135

136

137

138

139

140

141

142

143

144

145

146

147

148

149

150

151

152

153

154

155

156

157

158

159

was confirmed by gas chromatography-mass spectrometry (GC-MS) of their methyl esters and DMOX derivatives on a GCMS-2010 Ultra instrument (Shimadzu, Kyoto, Japan) (electron impact at $70 \mathrm{eV}$ ) and a MDN-5s (Supelco, Bellefonte, USA) capillary column $(30 \mathrm{~m} \times 0.25 \mathrm{~mm}$ ID). Carrier gas was He at $30 \mathrm{~cm} \cdot \mathrm{s}^{-1}$. The $\mathrm{GC}-\mathrm{MS}$ analysis of FAME was performed at $160{ }^{\circ} \mathrm{C}$ with a $2{ }^{\circ} \mathrm{C} \cdot \mathrm{min}^{-1}$ ramp to $240{ }^{\circ} \mathrm{C}$ that was held for $20 \mathrm{~min}$. The injector and detector temperatures were $250{ }^{\circ} \mathrm{C}$. GC-MS of DMOX derivatives was performed at $210{ }^{\circ} \mathrm{C}$ with a $3{ }^{\circ} \mathrm{C}$. $\mathrm{min}^{-1}$ ramp to $270{ }^{\circ} \mathrm{C}$ that was held for $40 \mathrm{~min}$. The injector and detector temperatures were 270 ${ }^{\circ} \mathrm{C}$. Spectra were compared with the NIST library and the online FA mass spectra archive website (Christie, 2021).

\section{Statistical analysis}

Differences in FA composition (only for species with 3 replicates) were investigated using PERMANOVA (Anderson, Gorley \& Clarke, 2008; Clarke \& Gorley, 2015). The

PERMANOVA analysis was based on Bray-Curtis similarity matrices, using 9999 random permutations of raw data. After the PERMANOVA routines, pairwise Monte Carlo tests were performed between all pairs of species. PERMDISP routines was performed to test homogeneity of multivariate dispersions. A nMDS ordination plot was used to visualize the similarity relationship among individuals and groups of individuals. The FAs that characterized and discriminated these groups were identified by SIMPER. The tests mentioned above were carried out using Primer 7+ software (PRIMER-e, New Zealand). Significance of differences in mean contents of FA between the nudibranch species was tested by one-way analysis of variance (ANOVA). Raw data were used after being tested for the homogeneity of variances (Levene's test) and normality of data distribution (Shapiro-Wilk test). Significant differences between levels were examined post hoc with Tukey-Kramer HSD multiple comparisons test. To represent differences between the nudibranch species, the variables (square roots of FA contents) were included in principal components analyses (PCA). These statistical analyses were performed using STATISTICA 5.1 (StatSoft, Inc., USA). Cluster analysis was performed using Ward's method (Minimum variance method) and the pvclust( ) function in the pvclust package provides p-values for hierarchical clustering based on multiscale bootstrap resampling (Suzuki \& Shimodaira, 2006) available in the R-Studio software (R-Tools Technology, Canada). A statistical probability of $p<0.05$ was considered significant. Values are represented as mean \pm standard deviation.

\section{Results}

The full FA composition of total lipids in the five nudibranch species from different depths is summarized in Supplement Table S1. The average contents of the major 20 FAs are shown in Table 1. The main saturated FA (SFA) was 16:0, and the major monounsaturated FAs (MUFAs) were 20:1n-9 and 20:1n-7. Lipids of all nudibranchs contained branched and odd-chain SFAs; the highest levels of these acids were detected in some specimens of A. papillosa and C. pacifica (up to 11 and $17 \%$ of total FAs, respectively). 
160

161

162

163

164

165

166

167

168

169

170

171

172

173

174

175

176

177

178

179

180

181

182

183

184

185

186

187

188

189

190

191

192

193

194

195

196

197

198

199

Acids 20:4n-6, 20:5n-3, and 22:6n-3 dominated polyunsaturated FAs (PUFAs) of the nudibranchs studied except for T. tetraquetra. The lowest level of 22:6n-3 (HSD test, $p=$ $0.0004)$ and considerable amounts $\left(F_{4,11}=22.2735, p<0.0001\right)$ of very-long-chain tetracosapolyenoic acids (TPA), 24:5n-6 and 24:6n-3, were found in T. tetraquetra. The ratio 24:6n-3/24:5n-6 in Tritonia specimens from a depth of 450-516 m (7.0 \pm 2.2$)$ was higher than that in Tritonia specimens from a depth of 210-247 $\mathrm{m}(1.3 \pm 0.1)$. The level of $20: 5 \mathrm{n}-3$ was significantly lower (HSD test, $p=0.012$ ) in the deep-sea $C$. pacifica than that in the shallowwater $C$. verrucosa. Unusually high percentages of 22:5n-6 were detected in two specimens of $C$. pacifica (9.6 and $18.6 \%$ of total FAs). Individuals of $A$. papillosa contained the highest level of $22: 5 n-3$ (up to $9.9 \%$ of total FAs). Several non-methylene-interrupted FAs (NMI FAs) were present in total FAs of all mollusk species. The highest level (HSD test, $p=0.0007$ ) of $\Delta 5,11$ 20:2 in T. tetraquetra specimens distinguished them from other nudibranchs. All species (except for $C$. verrucosa) contained noticeable amounts of $\Delta 7,13-22: 2$.

The PERMANOVA results (Table 2) were corroborated by the nMDS plot (Supplement Fig. S1) and revealed significant differences $(p<0.001)$ between species. The pairwise comparison has shown significant $(p<0.05)$ differences for all pairs of species (Table 2$)$, with the exception of the pair Dendronotus sp. and C. verrucosa. To detail the impact of each FA in similarity and dissimilarity among all nudibranch studied, the FA composition data were analyzed by SIMPER. Supplement Table S2 shows the first five FAs that contribute more than $7 \%$ in the similarity or dissimilarity. The high level of arachidonic acid (20:4n-6) in $T$. tetraquetra specimens distinguished them from other nudibranchs studied. The level of 20:4n-6 in Tritonia specimens from a depth of 450-516 m (10.4-13.6\%) was lower than that in Tritonia specimens from a depth of 210-247 m (18.5-20.0\%) (Supplement Table S1).

Analyses of the FA composition data by ANOVA identified certain FAs that were mainly responsible for the difference between species from deep and shallow waters (Table 1). Compared to the group of shallow-water species, deep-sea ones contained significantly higher $(p$ $<0.05)$ levels of 20:4n-6 and $\Delta 7,15-22: 2$, but significantly lower $(p<0.05)$ levels of 14:0, 16:1n$7,20: 1 n-11,20: 1 n-7,20: 5 n-3,22: 4 n-6$, and 22:5n-3. No differences $(p>0.05)$ were found for other FAs listed in Table 1.

Results of a cluster analysis of the FA composition data (Table 1) for the five nudibranch species are shown in Figure 3. All studied specimens were subdivided into three groups: the first and second groups consisted of deep-sea specimens of T. tetraquetra and C. pacifica, respectively, and the third group combined specimens of the deep-sea Dendronotus sp. with the shallow-water species A. papillosa and C. verrucosa.

The FAs listed in Table 1 were used as variables for PCA. In this analysis, the first two PCA components explained $50 \%$ of the variance of the FA composition data. Figure 4A shows that $T$. tetraquetra is clearly separated from all other nudibranch species along the first PCA component, linking positively with 20:4n-6, 24:5n-6, and 24:6n-3, and negatively with 22:4n-6 and 22:6n-3 (Fig. 4B). The second PCA component separates $C$. pacifica from the group of Dendronotus sp., A. papillosa, and C. verrucosa (Fig. 2A). Figure 2B shows that the level of 
200 SFAs (16:0 and 18:0), MUFAs (20:1n-9 and 20:1n-7), and 20:5n-3 vs. the level of 22:5n-6 and 201 NMI FAs is significant for this separation. The level of 22:5n-6 was significantly higher $\left(F_{1,14}=\right.$ $2026.555, p=0.023$ ) in the group of Dendronotus sp., A. papillosa, and C. verrucosa than that in $T$. 203 tetraquetra and C. pacifica. The PCA results (Fig. 4) agree with the results of cluster analysis 204 (Fig. 3) and show a significant difference in FA profiles between deep-sea T. tetraquetra, $C$. 205 pacifica, and the two shallow-water species. Both statistical methods confirm that the FA 206 profiles of the deep-sea Dendronotus sp. and the shallow-water species are similar.

207

\section{Discussion}

209 The representatives of nudibranchs of genera Aeolidia, Coryphella, and Dendronotus prey on 210 various groups of Cnidaria (Hall \& Todd, 1986). The nudibranch A. papillosa is known to prey 211 on sea anemones, grabbing their soft tissues by highly denticulated uniserial radula (Fig. 2A), 212 and consume their nematocyst (stinging capsular organelles) to protect against other predators 213 (Hall \& Todd, 1986; Vorobyeva, Malakhov \& Ekimova, 2021). The considerable levels of 22:5n2146 and $\mathrm{C}_{20-22}$ MUFAs are characteristic for the FA composition of shallow- and deep-water sea 215 anemones (Kiyashko et al., 2014; Revel et al., 2016). Obviously, the noticeable amounts of $21622: 5 n-6$ and $\mathrm{C}_{20}$ MUFAs that we found in A. papillosa most likely originate from sea anemone 217 lipids consumed by this nudibranch species.

218 The nudibranchs $A$. papillosa and $C$. verrucosa occur in the same shallow-water 219 community, but $C$. verrucosa demonstrates non-specified feeding mode (Mikhlina, Vortsepneva $220 \&$ Tzetlin, 2015), and its radula (Fig. 2C,D) does not take part in biting the prey. This species is 221 known as a non-specialized cnidarian feeder preying on scyphoid jellyfish (Hernroth \& 222 Grondahl, 1985; Ostman, 1997), soft corals (Sebens, 1983; Allmon \& Sebens, 1988), and 223 hydroids of orders Anthoathecata (the genera Tubularia, Clava, and Hydractinia) and 224 Leptothecata (the genus Obelia) (Kuzirian, 1979). $\mathrm{C}_{24}$ PUFAs are proposed as biomarkers for 225 marine food web studies (Drazen et al. 2008; Blanchet-Aurigny et al. 2015). Very-long-chain $226 \mathrm{C}_{24}$ PUFAs are FATM of jellyfish and soft corals (Svetashev \& Vysotskii, 1998; Imbs et al. 2010, 227 2016; Svetashev, 2019). Trace amounts of $\mathrm{C}_{24}$ PUFAs in C. verrucosa indicate that this species 228 from the Kuril Islands probably preys on anthoathecates hydroids, which may be a source of the 229 230 231 232 increasing levels of 22:5n-6 and $\mathrm{C}_{20}$ MUFAs in this nudibranch species. C. verrucosa is characterized by the least intraspecific similarity in the composition of fatty acids. It may also indicate a wide range of food supplies for this species.

235

236

237

238

239

The radula morphology in Dendronotus sp. (Fig. 2B) is very similar to that of Dendronotus lacteus and D. rufus and has a large number of knife-like lateral teeth that nudibranchs may use for biting off soft tissues of polyps (Ekimova et al., 2019b). There is some evidence that $D$. lacteus and D. rufus feed on hydroids of family Sertulariidae (order Leptothecata), scyphistomaes, and anemones (Ekimova et al., 2019b). Considering the close similarity between the FATM profiles of $A$. papillosa, C. verrucosa, and Dendronotus sp., we assume that the increased 22:5n-6 and $\mathrm{C}_{20}$ MUFAs levels recorded in the deep-sea nudibranch Dendronotus sp. from the Sea of Okhotsk likely indicate its preying on sea anemones and/or anthoathecates 
240 hydroids, similarly to shallow-water species A. papillosa and C. verrucosa. A dietary

241 resemblance and smoothing of lipid profiles by dietary FAs may be a possible reason of the

242 resemblance in FATM between evolutionary distant species.

243 Several species of the genus Tritonia are known to be obligate predators feeding on soft

244 corals (Allmon \& Sebens, 1988; Goddard, 2006). Recently, an analysis of the FA composition of

245 the nudibranch $T$. tetraquetra preying on soft corals (the Sea of Okhotsk) has shown an intensive 246 transfer of a soft coral FATM (24:5n-6 and 24:6n-3) from prey to predator (Imbs, 2016). The

247 ratio $24: 6 \mathrm{n}-3 / 24: 5 \mathrm{n}-6$ was compared between $T$. tetraquetra $(1.1 \pm 0.2)$ and several soft coral

248

249

250

251

252

253

254

255

256

257

258

259

260

261

262

263

264

265

266

267

268

269

270

271

272

273

274

275

276

277

278

279 species. As a result, the soft corals Gersemia rubiformis and Acanella sp. were suggested as the probable food sources of T. tetraquetra (Imbs, 2016; Imbs \& Chernyshev, 2019). No significant differences in the ratio $24: 6 n-3 / 24: 5 n-6$ were earlier found between $T$. tetraquetra specimens collected at different depths.

In the present study, the high levels of 24:6n-3 and 24:5n-6, which are observed in $T$. tetraquetra from Simushir Island, confirm preying on soft corals. Based on the ratio 24:6n3/24:5n-6, we can assume that T. tetraquetra at a depth of $250 \mathrm{~m}$ mainly feed on the Gersemia and/or Acanella soft corals. The increase in the ratio 24:6n-3/24:5n- 6 accompanying by the decrease in the 20:4n-6 level the in T. tetraquetra with increasing depth indicates a change in the taxonomic group of soft corals consumed. Among deep-sea soft corals that occur in the Sea of Okhotsk, the very high ratio $24: 6 n-3 / 24: 5 n-6=95 \div 310$ and the lowest level of 20:4n-6 (1.7 \pm $0.3 \%$ ) is characteristic of soft corals within the family Primnoidae (Imbs et al., 2016), which most likely make a considerable contribution in diet of $T$. tetraquetra at a depth of $500 \mathrm{~m}$. Our field observations show that $T$. tetraquetra is often found in communities of various groups of soft corals (Octocorallia) (Supplement Fig. S3), which apparently dominate food sources of this nudibranch.

Species of genus Colga can feed on members of phylum Bryozoa (Grischenko \& Martynov, 1997; Behrens, 2004). At least 18 species of bryozoans were earlier found in a digestive tract of C. pacifica (Martynov \& Baranets, 2002). A noticeable level of $\Delta 7,13-22: 2$ and 22:6n-3 has been detected in total FAs of the bryozoan Dendrobeania flustroides from the Sea of Okhotsk (Demidkova, 2010). The high content of these two FAs in C. pacifica confirms that this deep-sea species likely feeds on bryozoans. The low intraspecific similarity in the FA composition revealed for C. pacifica may indicate a lack of food specialization towards any particular species of bryozoan.

Other characteristic FAs of $C$. pacifica such as 22:5n-6 and odd-chain/branched SFAs may originate from own biosynthesis and associated microorganisms, respectively. The unexpectedly high content of 22:5n-6 found in C. pacifica may be a result of high activity of $\mathrm{C}_{2}$ elongase and $\Delta 4$ desaturase that convert 20:4n-6 into 22:5n-6. Such activity has been hypothesized in the hydrocoral Millepora to explain the extremely high levels of 22:5n-6 and 22:6n-3 (Imbs, Dang \& Nguyen, 2019; Imbs et al., 2021). The relatively low level of 20:5n-3 in C. pacifica can be due to either conversion of 20:5n-3 to $22: 6 n-3$ or a deficiency on dietary 20:5n-3 in deep waters (Kiyashko et al., 2014). Odd-chain and branched SFAs in marine invertebrates indicate the 
280 presence of associated bacteria (Kharlamenko \& Kiyashko 2018). Various bacteria have been 281 found in visceral organs of nudibranchs (Zhukova \& Eliseikina, 2012). An abundant bacterial 282 community may be a cause of the highest level of "bacterial" SFAs in C. pacifica.

283

284

285

286

287

288

289

290

291

292

293

294

295

296

297

298

299

300

301

302

303

304

305

306

307

308

309

310

311

312

313

314

315

316

317

318

319

\section{Conclusions}

FA profiles of five nudibranch mollusk species belonging to families Polyceridae, Tritoniidae, Dendronotidae, Coryphellidae, and Aeolidiidae were determined. The feeding specialization of deep-sea and shallow-water species were compared on the base of FATM present in their body tissues. Different species originating from different depths, but with similar food sources, showed similar FATM profiles. Species composition of soft corals consumed by T. tetraquetra appear to change with increasing depth. Deep-sea nudibranchs of genus Colga are most promising objects for future studies, as the proportion between dietary and self-synthesize PUFAs that they feature should be assessed. Future studies employing molecular barcodes to identify nudibranchs gut content can confirm our assumptions on the feeding regimes of the deep-sea species here reported, as FATM provide indirect evidence of trophic interactions and often impair the identification of prey at genus or species level.

\section{Acknowledgements}

\section{Funding}

This work was supported by the Ministry of Science and Higher Education, Russian Federation (grant 13.1902.21.0012 for ID, contract No 075-15-2020-796).

\section{Author Contributions}

Anatolii Komisarenko collected the samples, performed the lipid analyses, analysed the data, authored or reviewed drafts of the paper, approved the final draft.

Vladimir Mordukhovich conceived and designed the experiments, analysed the data, authored or reviewed drafts of the paper, approved the final draft.

Irina Ekimova collected the samples, determine the biological species, performed biological and morphological studies, approved the final draft.

Andrey Imbs conceived and designed the experiments, contributed reagents/materials/analysis tools, analysed the data, prepared figures and/or tables, authored or reviewed drafts of the paper, approved the final draft.

\section{Data Availability}

The following information was supplied regarding data availability: Raw data in the format of Excel Table documents are provided as the XLSX file in the Supplemental Materials.

\section{Supplemental Information}

Supplemental information for this article can be found online. 
320

321

322

323

324

325

326

327

328

329

330

331

332

333

334

335

336

337

338

339

340

341

342

343

344

345

346

347

348

349

350

351

352

353

354

355

356

357

358

\section{References}

Allmon RA, Sebens KP. 1988. Feeding biology and ecological impact of an introduced nudibranch, Tritonia plebeia, New England, USA. Marine Biology 99(3):375-385 DOI: 10.1007/BF02112130.

Anderson MJ, Gorley RN, Clarke KR. 2008. PERMANOVA + for PRIMER: Guide to Software and Statistical Methods. UK: PRIMER-E Ltd.

Barnes DKA, Bullough LW. 1996. Some observations on the diet and distribution of nudibranchs at Signy Island, Antarctica. Journal of Molluscan Studies 62:281-287 DOI: 10.1093/mollus/62.3.281.

Behrens DW. 2004. Pacific Coast Nudibranchs, Supplement II. New Species to the Pacific Coast and New Information on the Oldies. California Academy of Sciences 55:11-54.

Bertsch H. 2020. A history of eastern Pacific marine heterobranch research. The nautilus 134(2):71-88.

Blanchet-Aurigny A, Dubois SF, Quere C, Guillou M, Pernet, F. 2015. Trophic niche of two co-occurring ophiuroid species in impacted coastal systems, derived from fatty acid and stable isotope analyses. Marine Ecology Progress Series 525:127-141 DOI: 10.3354/meps11169.

Bligh EG, Dyer WJA. 1959. A rapid method of total lipid extraction and purification. Canadian Journal of Biochemistry and Physiology 37:911-917 DOI: 10.1139/y59-099.

Braeckman U, Provoost P, Sabbe K, Soetaert K, Middelburg JJ, Vincx M, Vanaverbeke J. 2015. Temporal dynamics in a shallow coastal benthic food web: Insights from fatty acid biomarkers and their stable isotopes. Marine Environmental Research 108:55-68 DOI: 10.1016/j.marenvres.2015.04.010.

Budge SM, Iverson SJ, Koopman HN. 2006. Studying trophic ecology in marine ecosystems using fatty acids: A primer on analysis and interpretation. Marine Mammal Science 22(4):759-801 DOI: 10.1111/j.1748-7692.2006.00079.x.

Calado R, Leal MC. 2015. Trophic ecology of benthic marine invertebrates with bi-phasic life cycles: What Are We Still Missing? Advances in Marine Biology 71:1-70 DOI: 10.1016/bs.amb.2015.07.001.

Carreau JP, Dubacq JP. 1978. Adaptation of macro-scale method to the micro-scale for FA methyl transesterification of biological lipid extracts. Journal of Chromatography A 151:384390 DOI: 10.1016/S0021-9673(00)88356-9.

Chimienti G, Angeletti L, Furfaro G, Canese S, Taviani M. 2020. Habitat, morphology and trophism of Tritonia callogorgiae sp. nov., a large nudibranch inhabiting Callogorgia verticillata forests in the Mediterranean Sea. Deep Sea Research Part I: Oceanographic Research Papers 165:103364 DOI: 10.1016/j.dsr.2020.103364.

Christie WW. 2020. Methyl esters of FA. Archive of mass spectra. The Lipid Web. Available at https://www.lipidhome.co.uk/ms/methesters/me-arch/index.htm. (accessed 22 June 2021).

Clarke KR, Gorley RN. 2015. PRIMER v7: User Manual/Tutorial. UK: PRIMER-E Ltd. 
359

360

361

362

363

364

365

366

367

368

369

370

371

372

373

374

375

376

377

378

379

380

381

382

383

384

385

386

387

388

389

390

391

392

393

394

395

396

397

Demidkova DA. 2010. The composition of fatty acids and aldehydes of the marine bryozoans Berenicea meandrina and Dendrobeania flustroides (Bryozoa: Gymnolaemata). Russian Journal of Marine Biology 36:300-304.

Drazen JC, Popp BN, Choy CA, Clemente T, De Forest L, Smith, KL. 2008. Bypassing the abyssal benthic food web: Macrourid diet in the eastern North Pacific inferred from stomach content and stable isotopes analyses. Limnology and Oceanography 53(6):2644-2654 DOI: 10.4319/1o.2008.53.6.2644.

Ekimova I, Deart Y, Schepetov D. 2019a. Living with a giant parchment tube worm: a description of a new nudibranch species (Gastropoda: Heterobranchia) associated with the annelid Chaetopterus. Marine Biodiversity 49(1):289-300 DOI: https://doi.org/10.1007/s12526-017-0795-z.

Ekimova I, Korshunova T, Schepetov D, Neretina T, Sanamyan N, Martynov A. 2015. Integrative systematics of northern and Arctic nudibranchs of the genus Dendronotus (Mollusca, Gastropoda), with descriptions of three new species. Zoological Journal of the Linnean Society 173(4):841-886 DOI: 10.1111/zoj.12214.

Ekimova I, Valdes A, Chichvarkhin A, Antokhina T, Lindsay T, Schepetov D. 2019b. Dietdriven ecological radiation and allopatric speciation result in high species diversity in a temperate-cold water marine genus Dendronotus (Gastropoda: Nudibranchia). Molecular Phylogenetics and Evolution 141:106609 DOI: 10.1016/j.ympev.2019.106609.

Goddard JHR. 2006. Stealthy slugs and communicating corals: polyp withdrawal by an aggregating soft coral in response to injured neighbors. Canadian Journal of Zoology 84:6671 DOI: 10.1139/Z05-178.

Grischenko AV, Martynov AV. 1997. Bryozoa as food items for the genera Colga and Triopha (Nudibranchia, Doridacea). [Abstract available from: http://www.bryozoa.net/russabst.html ] Russian and International Conference on Bryozoa.

Hall SJ, Todd CD. 1986. Growth and reproduction in the aeolid nudibranch Aeolidia papillosa (L). Journal of Molluscan Studies 52:193-205 DOI: 10.1093/mollus/52.3.193.

Hernroth L, Grondahl F. 1985. On the biology of Aurelia aurita (L) 2. Major factors regulating the occurrence of ephyrae and young medusae in the gullmar fjord, Western Sweden. Bulletin of Marine Science 37(2):567-576.

Hoover RA, Armour R, Dow I, Purcell JE. 2012. Nudibranch predation and dietary preference for the polyps of Aurelia labiata (Cnidaria: Scyphozoa). Hydrobiologia 690:199-213 DOI: 10.1007/s10750-012-1044-X.

Imbs AB. 2016. High level of tetracosapolyenoic fatty acids in the cold-water mollusk Tochuina tetraquetra is a result of the nudibranch feeding on soft corals. Polar Biology 39(8):15111514 DOI: 10.1007/s00300-015-1865-y.

Imbs AB, Chernyshev AV. 2019. Tracing of lipid markers of soft corals in a polar lipidome of the nudibranch mollusk Tritonia tetraquetra from the Sea of Okhotsk. Polar Biology 42(2):245-256 DOI: 10.1007/s00300-018-2418-y. 
398

399

400

401

402

403

404

405

406

407

408

409

410

411

412

413

414

415

416

417

418

419

420

421

422

423

424

425

426

427

428

429

430

431

432

433

434

435

436

Imbs AB, Dang LPT, Nguyen KB. 2019. Comparative lipidomic analysis of phospholipids of hydrocorals and corals from tropical and cold-water regions. Plos One 14(4):e0215759 DOI: 10.1371/journal.pone.0215759.

Imbs AB, Ermolenko EV, Grigorchuk VP, Dang LPT. 2021. Seasonal variation in the lipidome of two species of Millepora hydrocorals from Vietnam coastal waters (the South China Sea). Coral Reefs 40:719-734 DOI: 10.1007/s00338-021-02073-2.

Imbs AB, Grigorchuk VP. 2019. Lipidomic study of the influence of dietary fatty acids on structural lipids of cold-water nudibranch mollusks. Scientific Reports 9:20013 DOI: 10.1038/s41598-019-56746-8.

Imbs AB, Yakovleva IM, Latyshev NA, Pham LQ. 2010. Biosynthesis of polyunsaturated fatty acids in zooxanthellae and polyps of corals. Russian Journal of Marine Biology 36(6):452-457 DOI: 10.1134/S1063074010060076.

Kelly JR, Scheibling RE. 2012. Fatty acids as dietary tracers in benthic food webs. Marine Ecology Progress Series 446:1-22 DOI: 10.3354/meps09559.

Kharlamenko VI, Kiyashko SI. 2018. Fatty acid and stable isotope compositions in shallowwater bivalve mollusks and their food. Russian Journal of Marine Biology 44(2):100-111 DOI: $10.1134 /$ S1063074018020050.

Kiyashko SI, Kharlamenko VI, Sanamyan K, Alalykina IL, Wurzberg L. 2014. Trophic structure of the abyssal benthic community in the Sea of Japan inferred from stable isotope and fatty acid analyses. Marine Ecology Progress Series 500:121-137 DOI: 10.3354/meps 10663 .

Kuzirian AM. 1979. Taxonomy and biology of 4 New England coryphellid nudibranchs (gastropoda-opisthobranchia). Journal of Molluscan Studies 45:239-261.

Martynov AV, Baranets ON. 2002. A revision of the genus Colga Bergh (Opisthobranchia, Polyceridae), with description of a new species from the North Pacific. Ruthenica 12(1):2343.

McDonald G, Nybakken J. 1997. A worldwide review of the food of nudibranch mollusks 1 . Introduction and the suborder Arminacea. Veliger 40(2):157-159.

McDonald G, Nybakken J. 1999. A worldwide review of the food of nudibranch mollusks. Part II. The suborder Dendronotacea. Veliger 42:62-66.

Mikhlina A, Ekimova I, Vortsepneva E. 2020. Functional morphology and post-larval development of the buccal complex in Eubranchus rupium (Nudibranchia: Aeolidida: Fionidae). Zoology 143:125850 DOI: 10.1016/j.zool.2020.125850.

Mikhlina AL, Tzetlin AB, Ekimova IA, Vortsepneva EV. 2018. Drilling in the dorid species Vayssierea cf. elegans (Gastropoda: Nudibranchia): Functional and comparative morphological aspects. Journal of Morphology 280(1):119-132 DOI: 10.1002/jmor.20922.

Mikhlina AL, Vortsepneva EV, Tzetlin AB. 2015. Functional morphology of the buccal complex of Flabellina verrucosa (Gastropoda: Opisthobranchia). Invertebrate Zoology 12, 175-196 DOI: 10.15298/invertzool.12.2.04. 
437

438

439

440

441

442

443

444

445

446

447

448

449

450

451

452

453

454

455

456

457

458

459

460

461

462

463

464

465

466

467

468

469

470

471

472

473

474

475

Ostman C. 1997. Abundance, feeding behaviour and nematocysts of scyphopolyps (Cnidaria) and nematocysts in their predator, the nudibranch Coryphella verrucosa (Mollusca). Hydrobiologia 355:21-28 DOI: 10.1023/A:1003065726381.

Revel J, Massi L, Mehiri M, Boutoute M, Mayzaud P, Capron L, Sabourault C. 2016. Differential distribution of lipids in epidermis, gastrodermis and hosted Symbiodinium in the sea anemone Anemonia viridis. Comparative Biochemistry and Physiology A 191:140-151 DOI: $10.1016 /$ j.cbpa.2015.10.017.

Sebens KP. 1983. The larval and juvenile ecology of the temperate octocoral Alcyonium siderium Verrill 2. Fecundity, survival, and juvenile growth. Journal of Experimental Marine Biology and Ecology 72(3):263-285 DOI: 10.1016/0022-0981(83)90111-9.

Shuntov VP, Ivanov OA, Dulepova EP. 2019. Biological resources in the Sea of Okhotsk large marine ecosystem: their status and commercial use. Deep Sea Research 163:33-45 DOI: 10.1016/j.dsr2.2019.01.006

Suzuki R, Shimodaira H. 2006. Pvclust: an R package for assessing the uncertainty in hierarchical clustering. Bioinformatics 22(12): 1540-1542

DOI:10.1093/bioinformatics/btl117

Svetashev VI. 2011. Mild method for preparation of 4,4-dimethyloxazoline derivatives of polyunsaturated fatty acids for GC-MS. Lipids 46(5):463-467 DOI: 10.1007/s11745-0113550-4.

Svetashev VI. 2019. Fatty acids of the medusae Aurelia aurita (Linnaeus, 1758) and Rhopilema esculentum (Kishinouye, 1891): the presence of families of polyenoic acids with 24 and 26 carbon atoms. Russian Journal of Marine Biology 45(2):113-117 DOI: 10.1134/S1063074019020123.

Svetashev VI, Vysotskii MV. 1998. Fatty acids of Heliopora coerulea and chemotaxonomic significance of tetracosapolyenoic acids in coelenterates. Comparative biochemistry and Physiology B 119:73-75 DOI: 10.1016/S0305-0491(97)00231-9.B

Vorobyeva OA, Malakhov VV, Ekimova IA. 2021. General and fine structure of Aeolidia papillosa cnidosacs (Gastropoda: Nudibranchia). Journal of Morphology 282: 754-768 DOI: 10.1002/jmor.21346.

Zhukova NV. 2014. Lipids and fatty acids of nudibranch mollusks: potential sources of bioactive compounds. Marine Drugs 12(8):4578-4592 DOI: 10.3390/md12084578.

Zhukova NV, Eliseikina MG. 2012. Symbiotic bacteria in the nudibranch mollusk Dendrodoris nigra: FA composition and ultrastructure analysis. Marine Biology 159:1783-1794 DOI: 10.1007/S00227-012-1969-7.

\section{Figure titles and legends}

Figure 1 External views of studied nudibranchs. A and B, Aeolidia papillosa (dorsal and ventral view, respectively); C and D, Colga pacifica (dorsal and lateral view, respectively); E, 
476 Coryphella verrucosa; F, Dendronotus sp.; G and H, Tritonia tetraquetra (dorsal and ventral

477 view, respectively). Scale bar $10 \mathrm{~mm}$. Photos by A. Maiorova

478

479 Figure 2 Radular morphology of studied nudibranch species. A - Aeolidia papillosa,

480 posterior portion of uniserial radula. B - Dendronotus sp., middle portion of polycerial radula. C

481 - Coryphella verrucosa, triserial radula. D - Coryphella verrucosa, rachidian and lateral teeth. E

482 - Colga pacifica. F - Tritonia tetraquetra, posterior portion of polyserial radula. G - Tritonia

483 tetraquetra, rachidian teeth and innermost lateral teeth. $\mathrm{H}$ - Tritonia tetraquetra, middle lateral

484 teeth. Abbreviations: rh, rachidian tooth; lt, lateral tooth; mt, marginal teeth. Scale bars: A-C, G

$485-100 \mu \mathrm{m} ; \mathrm{D}-30 \mu \mathrm{m} ; \mathrm{E}, \mathrm{F}-500 \mu \mathrm{m} ; \mathrm{H}-200 \mu \mathrm{m}$.

486

487

Figure 3 Results of a cluster analysis of the FA composition data for the five nudibranch

488 species. The numerals on the branches represent are bootstrap probability (BP) value of a cluster 489 and approximately unbiased (AU) probability values. TT, Tritonia tetraquetra; CP, Colga

490 pacifica; CV, Coryphella verrucosa; DS, Dendronotus sp.; AP, Aeolidia papillosa.

491

492

Figure 4 Results of a principal component analysis (PCA) of the FA composition data for

493

the five nudibranch species. (A) The plot of the first two principal components; variables were

494 the major fatty acids (see Table 1). Ellipses were drawn manually to outline three groups

495 according to results of the cluster analysis (see Figure 3). (B) The projectiosn of 12 variables is shown. TT, Tritonia tetraquetra; CP, Colga pacifica; CV, Coryphella verrucosa; DS, 


\section{Table $\mathbf{1}$ (on next page)}

Fatty acid composition (\% of total FAs) of nudibranch mollusks

The species were collected at different depths near Simushir Island (Kuril Islands, Sea of Okhotsk). SFAs, saturated FAs; MUFAs, monounsaturated FAs; PUFAs, polyunsaturated FAs, n-3/n-6, the n-6 PUFAs/ n-3 PUFAs ratio. Values are means \pm SD; asterisks indicate significant differences $(p<0.05)$ between the groups of shallow-water species $(C$. verrucosa and $A$. papillosa) and deep-sea species (C. pacifica, T. tetraquetra, and Dendronotus sp.). 
TABLE 1 Fatty acid composition (\% of total FAs) of nudibranch mollusks. The species were collected at different depths near Simushir Island (Kuril Islands, Sea of Okhotsk). SFAs, saturated FAs; MUFAs, monounsaturated FAs; PUFAs, polyunsaturated FAs, n-3/n-6, the n-6 PUFAs/ n-3 PUFAs ratio. Values are means \pm SD; asterisks indicate significant differences $(p<0.05)$ between the groups of shallow-water species (C. verrucosa and A. papillosa) and deep-sea species (C. pacifica, T. tetraquetra, and Dendronotus sp.).

6

\begin{tabular}{|c|c|c|c|c|c|c|c|}
\hline \multirow[t]{3}{*}{ Fatty acids } & \multicolumn{5}{|c|}{ Species names and sampling depths } & \multirow{2}{*}{\multicolumn{2}{|c|}{$\begin{array}{l}\text { Comparison of shallow-water and } \\
\text { deep-sea groups by ANOVA }\end{array}$}} \\
\hline & \multicolumn{2}{|c|}{ Shallow-water group } & \multicolumn{3}{|l|}{ Deep-sea group } & & \\
\hline & $\begin{array}{l}\text { Coryphella } \\
\text { verrucosa, } \\
0-20 \mathrm{~m}, n=3\end{array}$ & $\begin{array}{l}\text { Aeolidia } \\
\text { papillosa, } \\
0-20 \mathrm{~m}, n=2\end{array}$ & $\begin{array}{l}\text { Colga pacifica, } \\
285-304 \mathrm{~m}, \\
n=3\end{array}$ & $\begin{array}{l}\text { Tritonia tetraquetra, } \\
210-516 \mathrm{~m}, \\
n=5\end{array}$ & $\begin{array}{l}\text { Dendronotus sp., } \\
210-516 \mathrm{~m}, \\
n=3\end{array}$ & $F_{1,14}$ & $p$ \\
\hline $14: 0 *$ & $4.2 \pm 2.4$ & $0.8 \pm 0.0$ & $1.3 \pm 0.6$ & $0.4 \pm 0.2$ & $0.9 \pm 0.4$ & 7.612 & 0.015 \\
\hline $16: 0$ & $11.2 \pm 2.9$ & $7.7 \pm 0.9$ & $9.3 \pm 1.3$ & $14.7 \pm 2.2$ & $12.6 \pm 1.7$ & 2.456 & 0.139 \\
\hline $16: \ln -7^{*}$ & $2.8 \pm 1.0$ & $0.7 \pm 0.1$ & $1.4 \pm 0.2$ & $0.6 \pm 0.1$ & $0.8 \pm 0.2$ & 7.436 & 0.016 \\
\hline $18: 0$ & $2.7 \pm 1.8$ & $5.1 \pm 0.0$ & $3.7 \pm 0.4$ & $5.5 \pm 1.0$ & $8.2 \pm 1.0$ & 3.798 & 0.072 \\
\hline $18: 1 n-9$ & $3.5 \pm 1.7$ & $1.5 \pm 0.1$ & $1.3 \pm 0.1$ & $2.8 \pm 0.6$ & $2.5 \pm 0.6$ & 0.495 & 0.493 \\
\hline $18: 3 n-3$ & $1.1 \pm 0.2$ & $3.5 \pm 0.6$ & $3.5 \pm 1.1$ & $0.5 \pm 0.1$ & $0.8 \pm 0.2$ & 0.679 & 0.424 \\
\hline $20: 1 n-11 *$ & $2.8 \pm 0.1$ & $1.3 \pm 0.0$ & $1.1 \pm 0.1$ & $0.6 \pm 0.1$ & $1.1 \pm 0.5$ & 6.982 & 0.019 \\
\hline $20: 1 n-9$ & $9.4 \pm 2.6$ & $1.8 \pm 0.1$ & $1.9 \pm 0.5$ & $1.5 \pm 0.1$ & $4.0 \pm 1.1$ & 3.053 & 0.102 \\
\hline $20: 1 n-7 *$ & $5.9 \pm 2.3$ & $4.3 \pm 0.0$ & $1.9 \pm 0.1$ & $2.6 \pm 0.2$ & $3.9 \pm 1.3$ & 5.417 & 0.035 \\
\hline$\Delta 5,11-20: 2$ & $1.3 \pm 0.9$ & $2.5 \pm 0.1$ & $0.6 \pm 0.2$ & $1.6 \pm 0.5$ & $5.5 \pm 0.3$ & 0.389 & 0.543 \\
\hline $20: 4 n-6^{*}$ & $3.2 \pm 0.9$ & $3.8 \pm 0.2$ & $4.3 \pm 3.0$ & $15.1 \pm 4.1$ & $8.3 \pm 2.5$ & 6.290 & 0.025 \\
\hline $20: 5 n-3 *$ & $25.8 \pm 12.4$ & $15.5 \pm 2.8$ & $7.4 \pm 3.1$ & $13.7 \pm 2.8$ & $18.4 \pm 0.5$ & 4.647 & 0.049 \\
\hline$\Delta 7,13-22: 2 *$ & $0.6 \pm 0.2$ & $2.6 \pm 0.4$ & $10.8 \pm 4.7$ & $8.8 \pm 2.1$ & $3.2 \pm 1.1$ & 11.629 & 0.004 \\
\hline$\Delta 7,15-22: 2$ & $0.3 \pm 0.2$ & $1.8 \pm 0.4$ & $0.7 \pm 0.1$ & $2.5 \pm 0.4$ & $1.1 \pm 0.4$ & 1.249 & 0.282 \\
\hline $22: 4 n-6^{*}$ & $3.1 \pm 1.8$ & $4.1 \pm 0.1$ & $0.9 \pm 0.5$ & $0.6 \pm 0.1$ & $1.6 \pm 1.5$ & 7.726 & 0.015 \\
\hline $22: 5 n-6$ & $0.1 \pm 0.1$ & $3.5 \pm 0.1$ & $9.8 \pm 5.9$ & $0.6 \pm 0.2$ & $2.8 \pm 1.0$ & 0.504 & 0.489 \\
\hline $22: 5 n-3^{*}$ & $2.5 \pm 1.1$ & $8.5 \pm 1.9$ & $1.4 \pm 0.6$ & $0.9 \pm 0.2$ & $2.0 \pm 0.5$ & 11.292 & 0.005 \\
\hline $22: 6 n-3$ & $8.5 \pm 2.1$ & $8.3 \pm 0.0$ & $12.0 \pm 3.8$ & $0.6 \pm 0.1$ & $11.0 \pm 0.7$ & 0.274 & 0.609 \\
\hline $24: 5 n-6$ & $0.0 \pm 0.0$ & $0.4 \pm 0.1$ & $0.5 \pm 0.4$ & $4.8 \pm 2.8$ & $0.0 \pm 0.0$ & 2.548 & 0.133 \\
\hline
\end{tabular}




\begin{tabular}{llllllll}
$24: 6 \mathrm{n}-3$ & $0.9 \pm 0.1$ & $0.4 \pm 0.0$ & $0.7 \pm 0.5$ & $12.9 \pm 2.6$ & $0.3 \pm 0.1$ & 2.933 & 0.109 \\
SFAs & $21.5 \pm 2.2$ & $22.5 \pm 0.9$ & $25.3 \pm 2.8$ & $23.8 \pm 2.1$ & $25.4 \pm 2.1$ & 5.951 & 0.029 \\
MUFAs & $27.1 \pm 13$ & $14.5 \pm 0.9$ & $12.3 \pm 1.4$ & $9.7 \pm 0.5$ & $15.8 \pm 1.3$ & 7.895 \\
PUFAs & $46.0 \pm 16.0$ & $44.3 \pm 4.4$ & $40.5 \pm 5.1$ & $51.7 \pm 3.0$ & $44.6 \pm 1.5$ & 0.104 \\
n-3/n-6 & $5.8 \pm 1.7$ & $2.9 \pm 0.3$ & $1.1 \pm 0.6$ & $1.4 \pm 0.8$ & $2.5 \pm 0.3$ & 18.998 & 0.014 \\
\hline
\end{tabular}




\section{Table 2 (on next page)}

Results of PERMANOVA pair-wise test of the fatty acid composition of nudibranch mollusks

$p(\mathrm{MC})$ are $p$ values obtained by Monte-Carlo sampling. CV, C. verrucosa; CP, C. pacifica; DS, Dendronotus sp.; $\mathrm{TT}, T$. tetraquetra. Asterisks indicates significant differences $(p<0.05)$. 
1

2 TABLE 2 Results of PERMANOVA pair-wise test of the fatty acid composition of 3 nudibranch mollusks. $p$ (MC) are $p$ values obtained by Monte-Carlo sampling. $\mathrm{CV}, C$. 4 verrucosa; CP, C. pacifica; DS, Dendronotus sp.; TT, T. tetraquetra. Asterisks indicates 5 significant differences $(p<0.05)$.

6

\begin{tabular}{lcc}
\hline Groups & $\mathrm{t}$ & $p(\mathrm{MC})$ \\
\hline $\mathrm{CV}, \mathrm{CP}^{*}$ & 2.1514 & 0.0296 \\
CV, TS* & 2.6979 & 0.0133 \\
CV, DS & 1.6093 & 0.1118 \\
CP, TS* & 3.4079 & 0.0086 \\
CP, DS* & 2.6239 & 0.0199 \\
TS, DS* & 4.1244 & 0.0024 \\
\hline
\end{tabular}

7 
Figure 1

External views of studied nudibranchs

A and B, Aeolidia papillosa (dorsal and ventral view, respectively); C and D, Colga pacifica (dorsal and lateral view, respectively); E, Coryphella verrucosa; F, Dendronotus sp.; G and H, Tritonia tetraquetra (dorsal and ventral view, respectively). Scale bar $10 \mathrm{~mm}$. Photos by A. Maiorova 

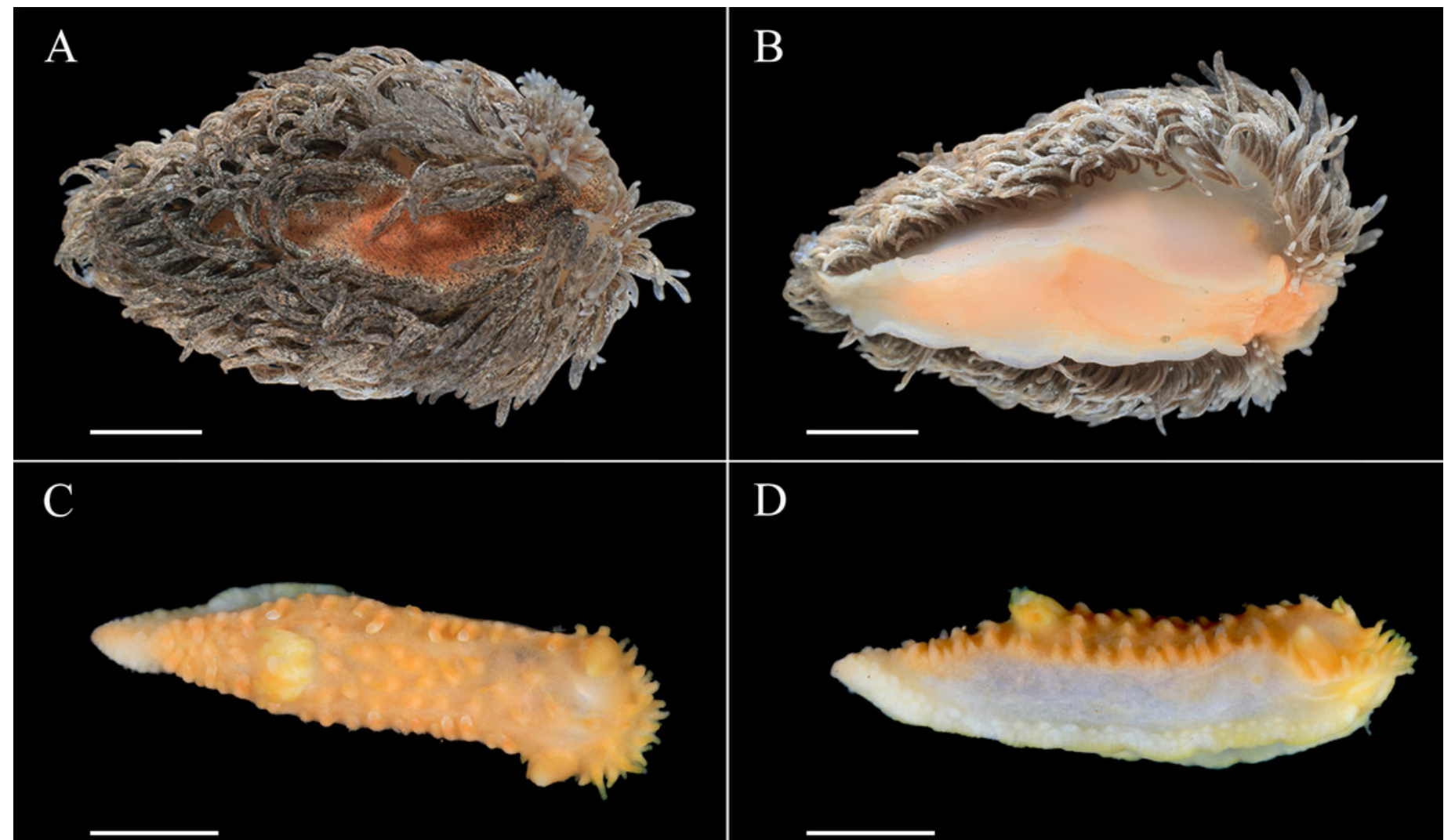

$\mathrm{D}$

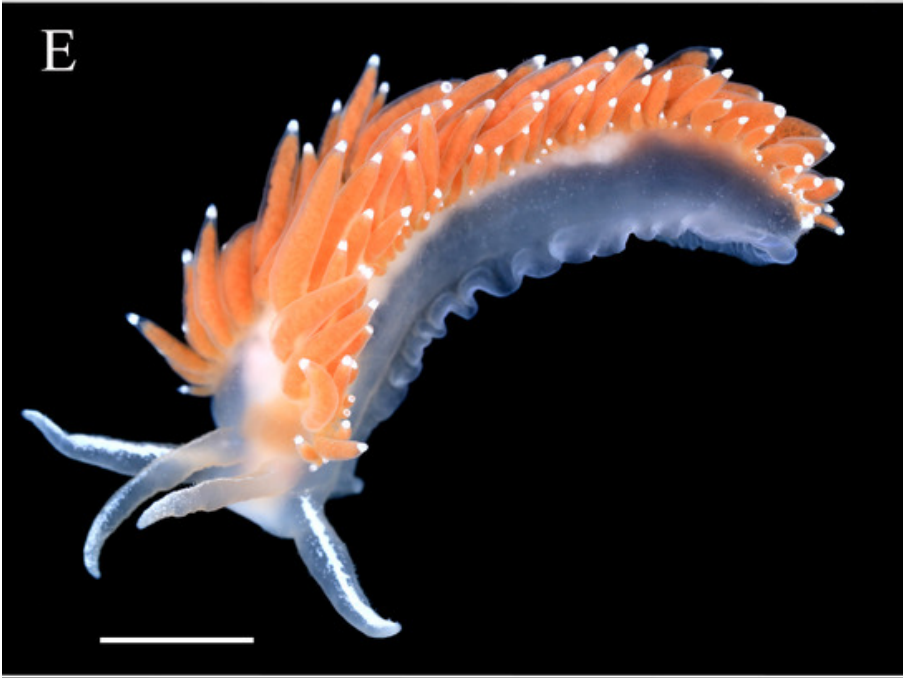

$\mathrm{F}$
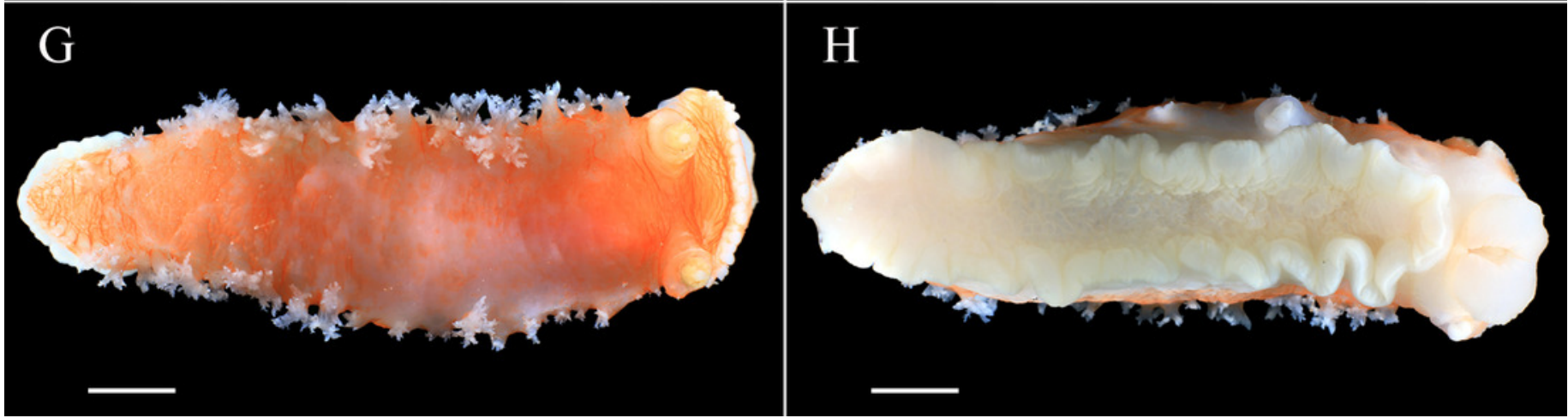


\section{Figure 2}

Radular morphology of studied nudibranch species

A - Aeolidia papillosa, posterior portion of uniserial radula. B - Dendronotus sp., middle portion of polycerial radula. C - Coryphella verrucosa, triserial radula. D - Coryphella verrucosa, rachidian and lateral teeth. E - Colga pacifica. F - Tritonia tetraquetra, posterior portion of polyserial radula. G - Tritonia tetraquetra, rachidian teeth and innermost lateral teeth. $\mathrm{H}$ - Tritonia tetraquetra, middle lateral teeth. Abbreviations: rh, rachidian tooth; It, lateral tooth; mt, marginal teeth. Scale bars: A-C, G - $100 \mu \mathrm{m}$; D - $30 \mu \mathrm{m} ; \mathrm{E}, \mathrm{F}-500 \mu \mathrm{m} ; \mathrm{H}-$ $200 \mu \mathrm{m}$. 

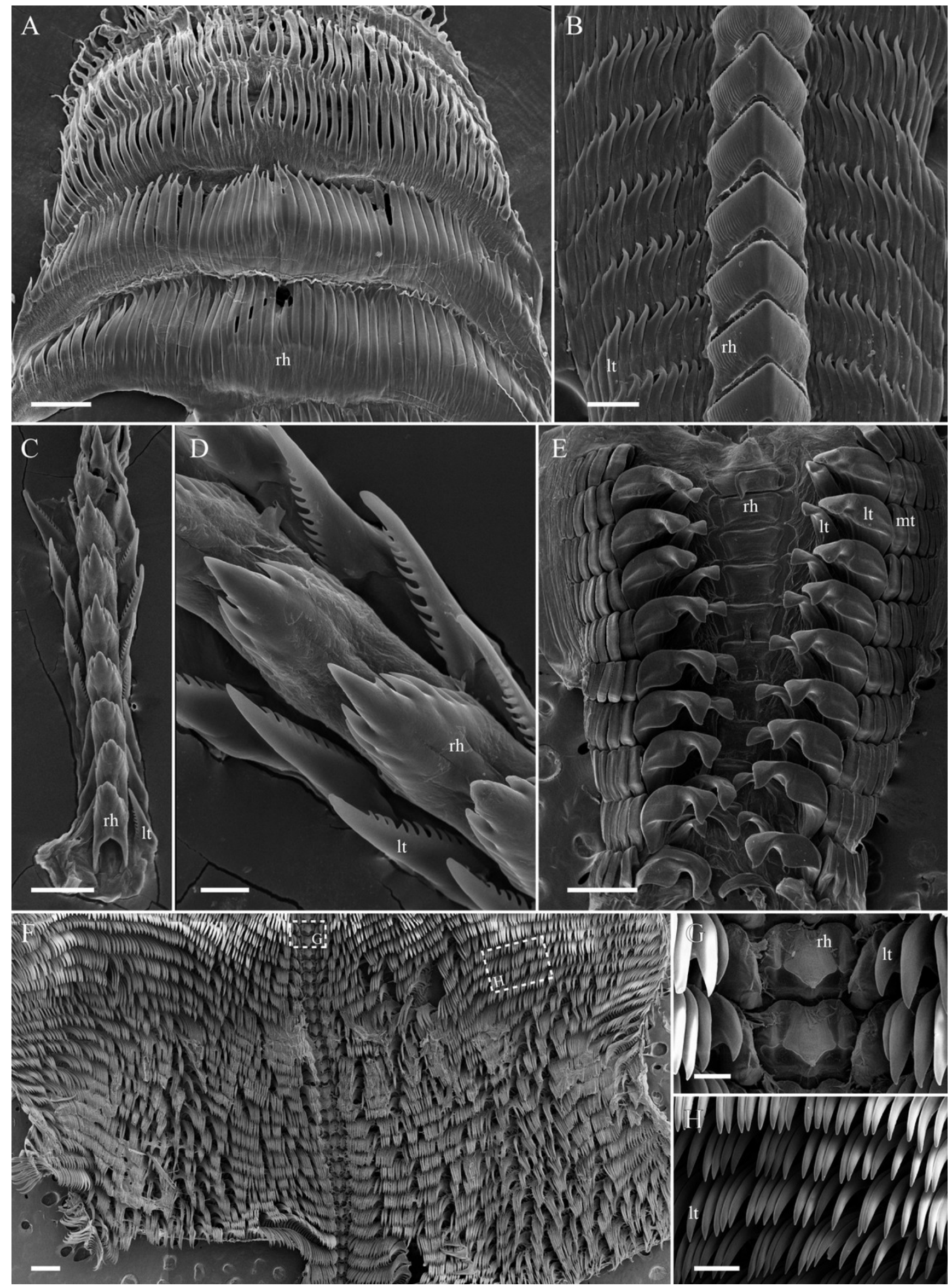
Figure 3

Results of a cluster analysis of the FA composition data for the five nudibranch species

The numerals on the branches represent are bootstrap probability (BP) value of a cluster and approximately unbiased (AU) probability values. $\mathrm{TT}$, Tritonia tetraquetra; $\mathrm{CP}$, Colga pacifica; CV, Coryphella verrucosa; DS, Dendronotus sp.; AP, Aeolidia papillosa. 


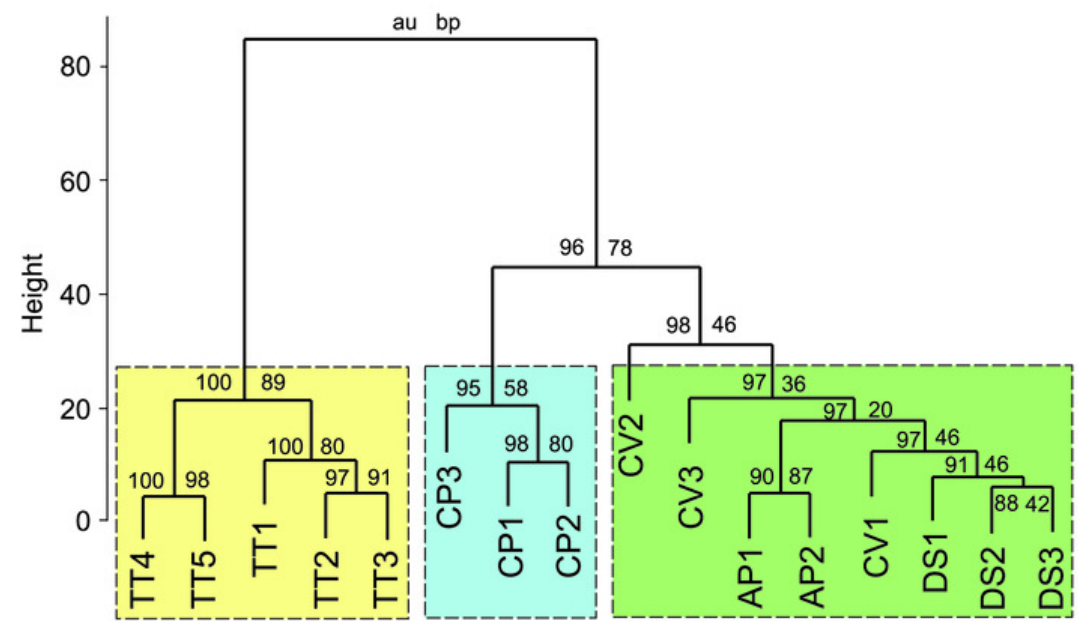

PeerJ reviewing PDF | (2021:06:63125:2:0:NEW 17 Sep 2021) 


\section{Figure 4}

Results of a principal component analysis (PCA) of the FA composition data for the five nudibranch species

(A) The plot of the first two principal components; variables were the major fatty acids (see Table 1). Ellipses were drawn manually to outline three groups according to results of the cluster analysis (see Figure 3). (B) The projectiosn of 12 variables is shown. TT, Tritonia tetraquetra; CP, Colga pacifica; CV, Coryphella verrucosa; DS, Dendronotus sp.; AP, Aeolidia papillosa. 

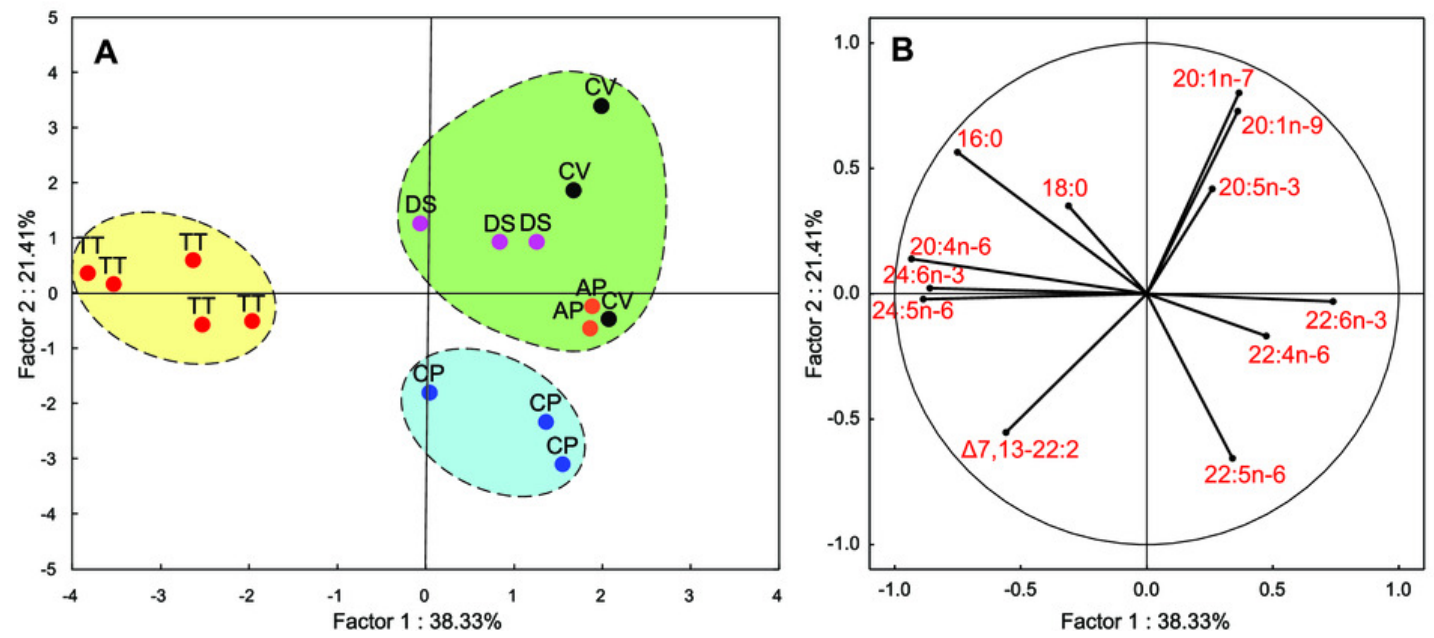

Peer] reviewing PDF | (2021:06:63125:2:0:NEW 17 Sep 2021) 